\title{
ERRATA FOR ZOOLOGIA VOLUME 27
}

\section{Zoologia 27(1)}

\section{Page 31, legend of figure 3:}

Reads: Figure 3. Seasonal variation in the size of ovarian follicles $(-)(n=11)$ or eggs $(O)(n=12)$ of E. cyanopleura from southern Brazil.

Should read: Figure 3. Seasonal variation in the size of ovarian follicles $(O)(n=11)$ or eggs $(\bullet)(n=12)$ of E. cyanopleura from southern Brazil.

\section{Zoologia 27(3)}

Page 395, page head:

Reads: doi: 10.1590/S1984-46702010000500002

Should read: doi: 10.1590/S1984-46702010005000002

Page 472, Introduction, first paragraph, line 3:

Reads: rec4uitment

Should read: recruitment

Page 477, page head:

Reads: doi: 10.1590/S1984-46702010000500001

Should read: doi: 10.1590/S1984-46702010005000001

\section{Zoologia 27(6)}

Page 965, author's name:

Reads: Ingo S. Wehrtmann ${ }^{1,5}$; Célio Magalhães ${ }^{2}$; Patricio Hernáez ${ }^{3,4}$ \& Fernando L. Mantelatto

Should read: Ingo S. Wehrtmann ${ }^{1,5}$; Célio Magalhães²; Patricio Hernáez ${ }^{1,3,4} \&$ Fernando L. Mantelatto ${ }^{4}$

Page 965, author's address:

Replace all author's addresses with:

${ }^{1}$ Unidad de Investigación Pesquera y Acuicultura of the Centro de Investigación en Ciencias del Mar y Limnología, Universidad de Costa Rica. 2060 San José, Costa Rica. E-mail: ingowehrtmann@gmx.de

${ }^{2}$ Coordenação de Pesquisas em Biologia Aquática, Instituto Nacional de Pesquisa da Amazônia. Caixa Postal 487, 69011-970 Manaus, AM, Brazil. E-mail: celiomag@inpa.gov.br

${ }^{3}$ Museo del Mar, Universidad Arturo Prat. Casilla 121, Iquique, Chile. E-mail: phernaez@lycos.com

${ }^{4}$ Laboratório de Bioecologia e Sistemática de Crustáceos, Departamento de Biologia, FFCLRP, Universidade de São Paulo. Programa de Pós-Graduação em Biologia Comparada. Avenida Bandeirantes 3900, 14040-901 Ribeirão Preto, SP, Brazil. E-mail: flmantel@usp.br

${ }^{5}$ Corresponding author. E-mail: ingowehrtmann@gmx.de

Page 970, Acknowledgements, line 12:

Reads: CM and FLM thank CNPq-Brazil for an ongoing research grant.

Should read: CM and FLM thank CNPq-Brazil for an ongoing research grant, and CAPES/DAAD (Proc. 315-09) for partial support during this project. PH is grateful for ongoing PhD fellowship from CAPES-Brazil. The first author (ISW) is also affiliated to the Museo de Zoología and the Escuela de Biología, both of the Universidad de Costa Rica.

All changes are already incorporated in the online version of these articles available at http://www.scielo.br/zool. 
